\title{
Descripción y análisis de costos de uniones convencionales y de innovación en la construcción con bambú rollizo
}

\author{
Description and cost analysis of conventional and innovative joints \\ construction with bamboo culm
}

Recibido: mayo 15 de 2020 | Revisado: julio 12 de 2020 | Aceptado: setiembre 11 de 2020

\author{
YANN BARNET $^{\mathrm{I}}$ \\ FAOUZI JABRANE ${ }^{I}$ \\ Camila Chumbimune ${ }^{\mathrm{I}}$
}

\begin{abstract}
RESUMEN
El estudio describe y analiza los costos de uniones empleadas en la construcción con bambú rollizo, tanto modelos convencionales como uniones de innovación desarrolladas para reducir los tiempos de ejecución y facilitar los procesos de trabajo. Los resultados son insumos esenciales para la elaboración de metrados y presupuestos de estructuras de bambú y ofrecen valores comparativos para guiar la toma de decisión en el diseño.
\end{abstract}

Palabras clave: bambú, Guadua, construcción, unión, conector, costo, mano de obra

\begin{abstract}
The study describes and analyzes the costs of joints used in the construction with bamboo culms, both conventional models and innovation joints developed to reduce execution times and facilitate the workflow. The results are essential inputs for the elaboration of meds and budgets of bamboo structures and offer comparative values to guide decision-making in the design.
\end{abstract}

Key words: Bamboo, Guadua, construction, joint, connector, cost, labor
1 Universidad de San Martín de Porres ivuc@usmp.pe

\footnotetext{
(C) Los autores. Este artículo es publicado por la Revista Campus de la Facultad de Ingeniería y Arquitectura de la Universidad de San Martín de Porres. Este artículo se distribuye en los términos de la Licencia Creative Commons Atribución No-comercial - Compartir-Igual 4.0 Internacional (https://creativecommons.org/licenses/ CC-BY), que permite el uso no comercial, distribución y reproducción en cualquier medio siempre que la obra original sea debidamente citada. Para uso comercial contactar a: revistacampus@usmp.pe.
} 


\section{Introducción}

\section{Antecedentes}

En la construcción con bambú rollizo, las uniones son un tema fundamental y a la vez complejo, dado que la naturaleza tubular e irregular de este perfil natural dificulta el desarrollo de conectores (Barnet \& Jabrane, 2019). En el método tradicional de uniones se requieren realizar cortes especiales que demandan tiempo y un saber hacer específico (Figura 2). Eso se traduce en costos de mano de obra relativamente alto. Para suplantar esta problemática se han creado cada vez más conectores con materiales, técnicas y funciones muy variadas.

En una búsqueda de optimización de los procesos de construcción, el Instituto de Vivienda Urbanismo y Construcción (IVUC) de la Universidad de San Martín de Porres (USMP) ha desarrollado unos conectores de extremidad y articulaciones para ser implementadas en varios tipos de proyectos (Figura 3), y en particular para el desarrollo de un sistema constructivo en base a bambú y madera de ingeniería que busca ser rápido y fácil de ensamblar. Este proyecto está volcado en la construcción de un prototipo de vivienda (Figura 1) cuyo fin es evaluar, optimizar y validar el sistema propuesto.

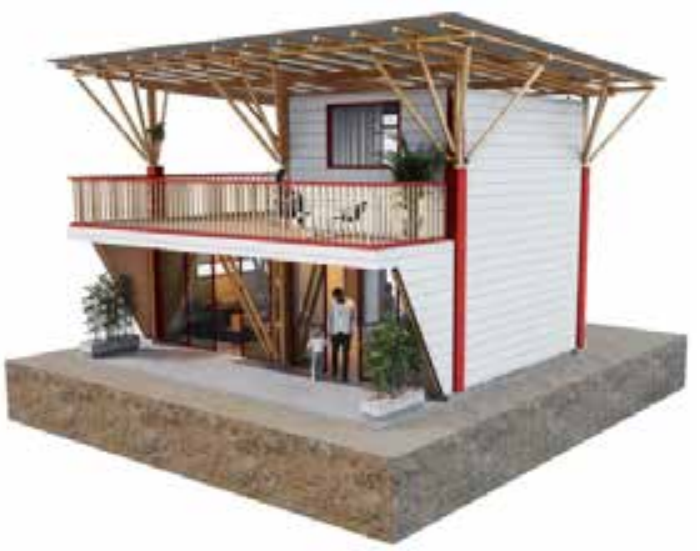

Figura 1. Diseño de prototipo de vivienda de bambú y madera de ingeniería. (IVUC)
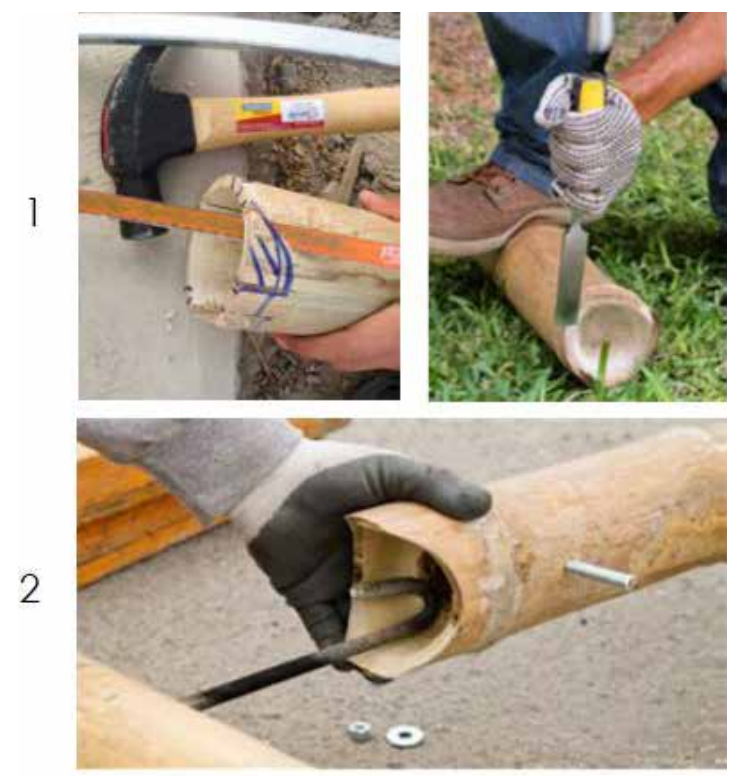

3

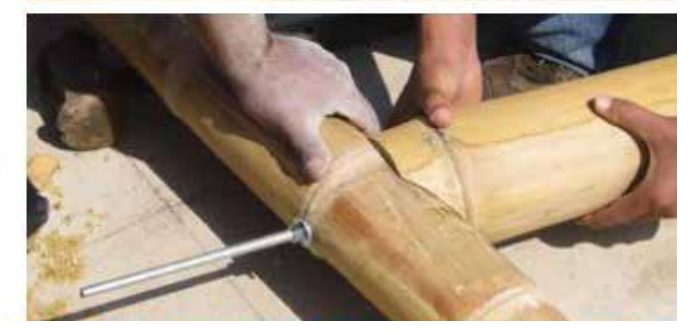

Figura 2. Unión usual con boca de pescado. (Barnet \& Jabrane, 2019)

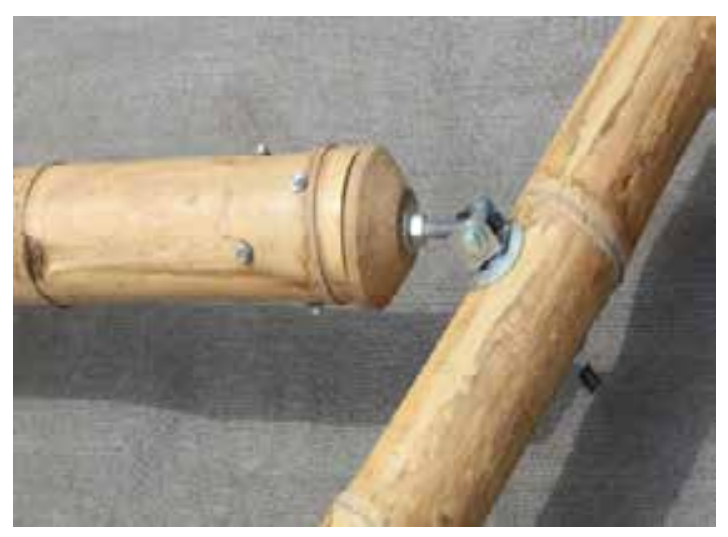

Figura 3. Conector de extremidad y articulación IVUC (Barnet \& Jabrane, 2019)

\section{Objetivos}

El presente estudio busca definir la cantidad de materiales y tiempos de mano de obra de todas las uniones empleadas en el proyecto de vivienda antes mencionado, con la finalidad de generar información esencial para la elaboración de su presupuesto, así como de cualquier otra estructura de bambú que emplea esas uniones. 
Además, los resultados obtenidos permiten medir el rendimiento económico de los conectores desarrollados por el IVUC comparado a uniones tradicionales que cumplen funciones análogas. El artículo tiene también como finalidad describir e ilustrar cada una de las uniones estudiadas, con sus procesos de montaje correspondiente. El estudio no contempla los aspectos de comportamiento estructural de las uniones.

\section{Materiales y método sujeto y materiales del estudio}

Dentro de las uniones estudiadas, cinco son usuales y descritas en la Norma Peruana E100 y tres corresponden a uniones nuevas desarrolladas por el IVUC. La lista completa está detallada en la Tabla 1. La especie de bambú utilizada es del género Guadua y tiene un diámetro promedio de $10 \mathrm{~cm}$.

Tabla 1

\begin{tabular}{|c|c|}
\hline $\mathbf{N}^{\circ}$ & DESCRIPCIÓN \\
\hline & UNIONES USUALES \\
\hline 1 & Pico de flauta con perno tensor \\
\hline 2 & Boca de pescado con perno tensor \\
\hline 3 & $\begin{array}{l}\text { Unión sobre base de concreto con fi- } \\
\text { erro y mortero }\end{array}$ \\
\hline 4 & $\begin{array}{l}\text { Unión longitudinal con eucalipto in- } \\
\text { terior }\end{array}$ \\
\hline \multirow[t]{2}{*}{5} & Unión tipo perno pasante \\
\hline & $\begin{array}{l}\text { UNIONES DE INNOVACIÓN } \\
\text { DEL IVUC }\end{array}$ \\
\hline 6 & $\begin{array}{l}\text { Unión perpendicular con tapa de } \\
\text { madera }\end{array}$ \\
\hline 7 & $\begin{array}{l}\text { Unión de tope de madera articulado a } \\
\text { una platina }\end{array}$ \\
\hline 8 & $\begin{array}{l}\text { Unión de tope de madera articulado a } \\
\text { un bambú }\end{array}$ \\
\hline
\end{tabular}

\section{Método}

Para cada una, se ha definido la cantidad de materiales empleados, y se ha medido el tiempo necesario de mano de obra, diferenciando la prefabricación y los procesos de colocación en obra de forma separada.

En el caso de las uniones usuales, se empleó el diseño contemplado en el Reglamento Nacional de Edificación (Ministerio de Vivienda, Construcción y Saneamiento, 2012) y se pidió a un experto de realizar cada unión en el piso para cronometrarlo (Figura 4). Para condiciones incómodas (en altura) el tiempo es muy variable y con el fin de tener una estimación, se entrevistó a especialistas con más de 10 años de experiencia. También se contrastó los valores con resultados del estudio "Aportes de mano de obra y materiales, para la creación de partidas en la construcción con bambü" (Chinchayán, 2016).

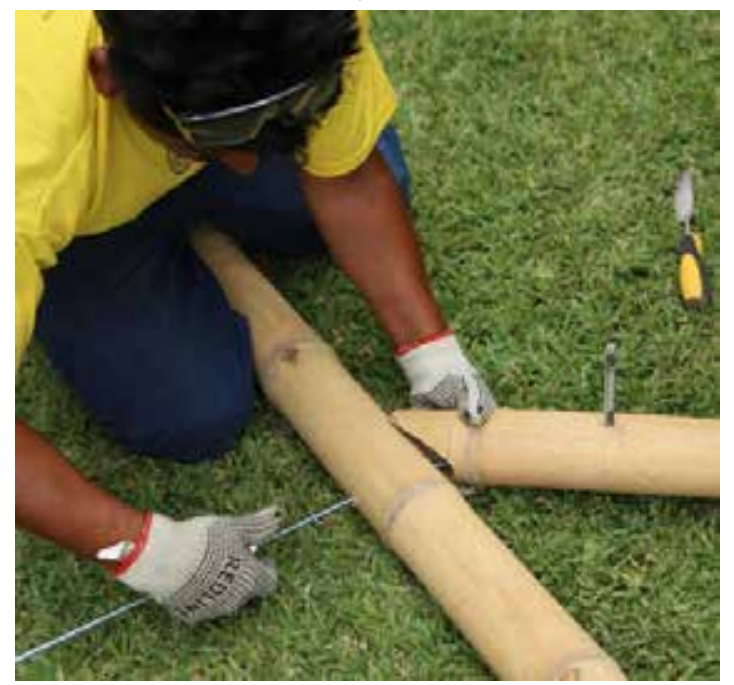

Figura 4. Proceso de ejecución de una unión usual con pico de flauta por un experto

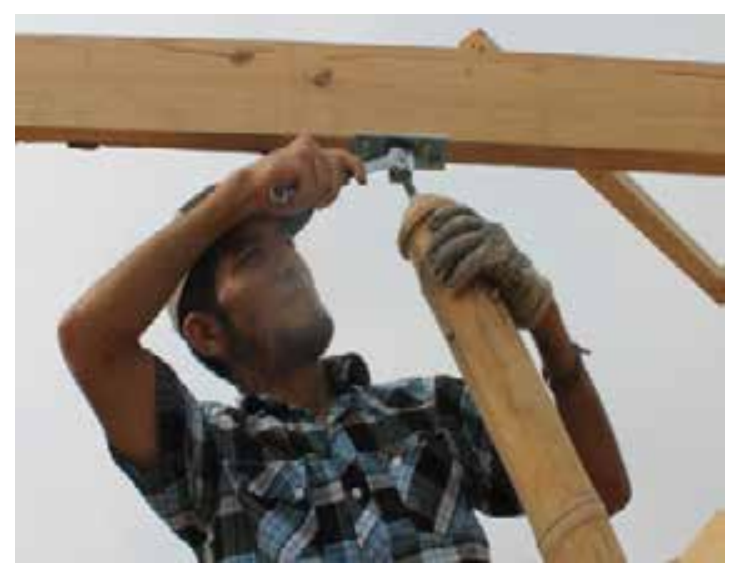

Figura 5. Proceso de una unión de tope de madera con articulación a una platina por un voluntario no profesional. 


\section{Costos unitarios empleados}

Todos los montos indicados en este artículo no incluyen impuestos, en particular el IGV (Impuesto General a la Venta) de 18\% en el Perú. Son montos referenciales en 2020 en la ciudad de Lima. En las siguientes tablas se detallan los costos unitarios utilizados para el estudio.

Tabla 2

Costos unitarios de materiales

\begin{tabular}{|c|c|c|}
\hline Ítem & Unidad & Costo Unitario S/. \\
\hline Varilla roscada 3/8" & $\mathrm{m}$ & 2.1 \\
\hline Tuerca de $3 / 8 "$ & Und & 0.1 \\
\hline Arandela de 3/8" & Und & 0.075 \\
\hline Varilla Roscada 1/2" & $\mathrm{m}$ & 3.9 \\
\hline Tuerca de $1 / 2 "$ & Und & 0.15 \\
\hline Arandela de 1/2" & Und & 0.1 \\
\hline Fierro $3 / 8$ " de $9 \mathrm{~m}$ & $\mathrm{~m}$ & 14.6 \\
\hline Cemento $42.5 \mathrm{~kg}$ & Und & 18.6 \\
\hline Arena gruesa $40 \mathrm{~kg}$ & Und & 5.5 \\
\hline Eucalipto de $21 / 2 ”$ & $\mathrm{~m}$ & 4.5 \\
\hline Plancha OSB $244 \times 122 \times 1.8 \mathrm{~cm}$ & Und & 64 \\
\hline Tornillo \#12 de 1 1/2” autoperforante & Und & 0.25 \\
\hline Perno de $3 / 8 " \times 2 "$ & Und & 0.5 \\
\hline Pernos de expansión 3/8 “ x 4" & Und & 2 \\
\hline Tirafón 4” (4mm) & Und & 1.5 \\
\hline Guadua tratada 6m, diam. Aprox. 4" & Und & 36 \\
\hline
\end{tabular}

Tabla 3

Costos unitarios piezas prefabricadas

\begin{tabular}{|c|c|c|}
\hline Ítem & Unidad & Costo Unitario S/. \\
\hline Varilla con bocina soldada (fig. 6) & Pieza & 3 \\
\hline Platina tipo 1 y 2 (fig. 8 ) & Pieza & 8 \\
\hline Pieza de articulación (fig. 6) & Pieza & 14 \\
\hline Tope de madera tornado (Figura 7) & Pieza & 7 \\
\hline
\end{tabular}

Tabla 4

Costos horarios de mano de obra

\begin{tabular}{cc}
\hline Ítem & Costo horario S/. \\
\hline Carpintero especialista en construcción con bambú & 24 \\
Operario & $22.94^{*}$ \\
Oficial & 18.14 \\
\hline
\end{tabular}

Nota: (Revista Costos, 2020) 


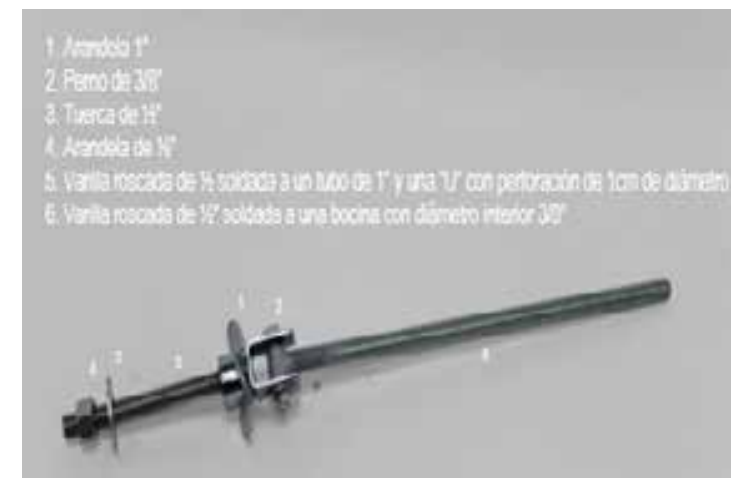

Figura 6. Pieza de articulación + varilla con bocina

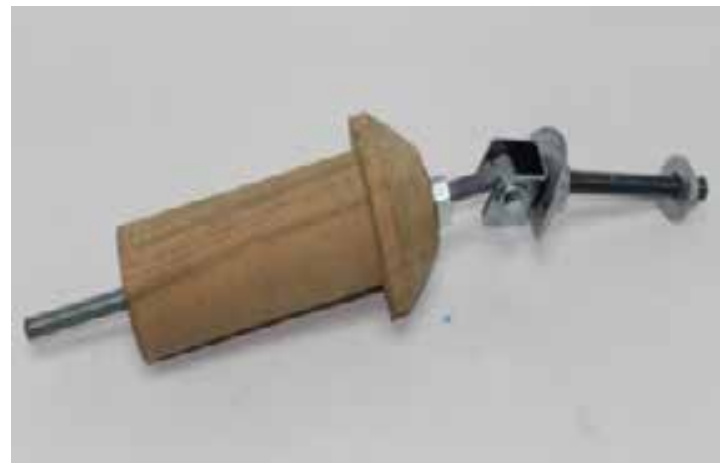

Figura 7. Pieza de madera tornada + piezas de articulación + varilla con bocina

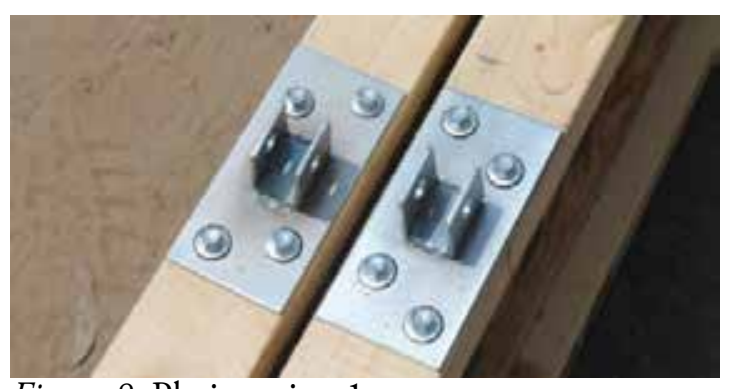

Figura 8. Platinas tipo 1

\section{Resultados}

\section{Tiempos según actividades}

La primera etapa del estudio ha sido cronometrar el tiempo necesario para realizar una actividad específica, que se detalla en la tabla 6. Es importante notar que son tiempos brutos de actividades realizadas en el piso, que no incorporan nociones de tiempos intermedios, descansos, fatiga, etc. Estos elementos tienen que ser añadidos cuando se desarrollan análisis de rendimiento para una obra.

Tabla 5

Tiempos para realizar actividades especificas en el piso (una persona) relativos a uniones convencionales

\begin{tabular}{llc}
\hline Actividad & Equipamiento & Tiempo en min \\
\hline Corte recto & Ingletadora & 0.5 \\
Corte recto ${ }^{*}$ & Amoladora & 0.5 \\
Corte recto & Serrucho & 1.5 \\
Corte Boca de pescado $^{*}$ & Formón, martillo, sierra & 8 \\
Corte Boca de pescado $^{*}$ (fig.9) & Amoladora o caladora & 4.5 \\
Corte Pico de flauta $^{1 *}$ & Formón, martillo, sierra & 17 \\
Corte Pico de flauta $^{1 *}$ & Amoladora o caladora & 8 \\
Sacar diafragma interno & Formón + martillo & 2 \\
Fijación con perno tensor $^{*}$ & Taladro + amoladora & 8 \\
Fijación de un perno pasante $^{*}$ & Taladro + amoladora & 4.5 \\
Llenado de un canuto con mortero $^{2}$ & Taladro & 6 \\
Corte y colocación eucalipto & Ingletadora & 1 \\
\hline
\end{tabular}

${ }^{*}$ actividad que requiere de una persona especializada

${ }^{1}$ Ángulo menor de $45^{\circ}$

${ }^{2}$ No contempla la preparación de la mezcla 
Tabla 6

Tiempos para realizar actividades específicas en el piso (una persona) relativos a las uniones de innovación

\begin{tabular}{llc}
\hline Actividad & Equipamiento & Tiempo en min \\
\hline Fijación platina tipo A & Atornillador eléctrico & 2 \\
Fijación platina tipo B & Taladro & 10 \\
colocación pieza de articulación & Taladro & 7 \\
Colocación conector de extremidad (Figura 10) & Atornillador eléctrico & 5 \\
Fijación de la pieza de bambú con conector & Llave & 1 \\
Regulación conector de extremidad & Llave & 5 \\
Unir tapa de madera con tirafón & Taladro & 5 \\
Conectar tapa de madera con otra pieza & Atornillador eléctrico & 2 \\
\hline
\end{tabular}

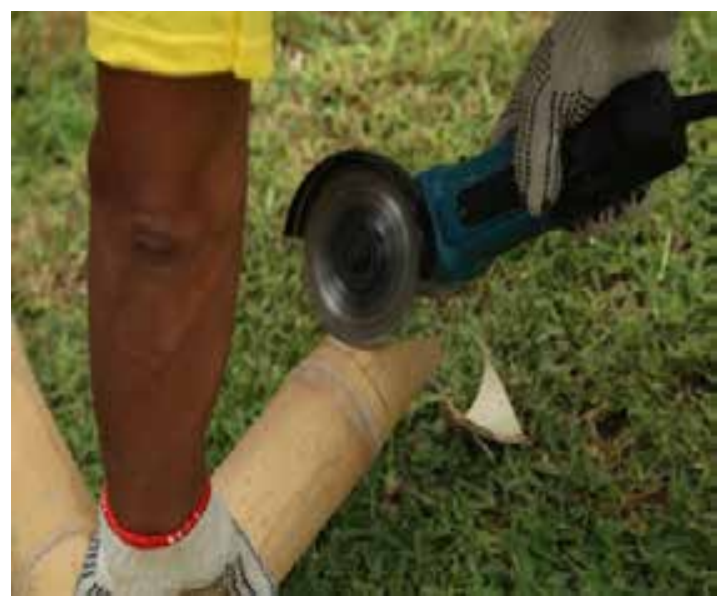

Figura 9. Corte Pico de Flauta con amoladora

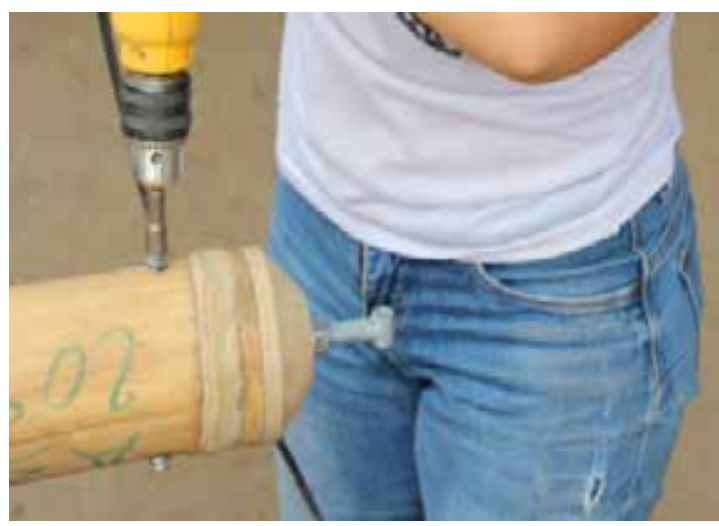

Figura 10. Colocación conector de extremidad

\section{Análisis de costo de habitación piezas de bambú}

Cualquiera sea la unión por realizar, una pieza de bambú pasa por un proceso de selección y medición que difiere de la mayor parte de los otros materiales de construcción por las siguientes razones:
- Ningún bambú es idéntico al otro y totalmente recto, por lo tanto, se tiene que identificar cuáles son los tallos más apropiados para la pieza deseada.

- Sebuscan tener nudos en ambos extremos de la pieza, por lo que la búsqueda de la pieza por extraer del bambú se suele hacer con dos personas con una wincha.

Una vez marcada la pieza, se pasa al proceso de corte. En el caso del presente estudio se emplea una ingletadora.

Tabla 7

Costo unitario mano de obra para la habilitación piezas de bambú. Se considera tiempo para dos oficiales

\begin{tabular}{lcccc}
\hline \multirow{1}{*}{ Pasos } & \multicolumn{2}{c}{ Tiempo } & P.U & Costo \\
& Min & HH & Operario & S/. \\
\hline Selección & 3.5 & 0.12 & 18.14 & 2.12 \\
y medición & & & & \\
2 Cortes & 1 & 0.033 & 18.14 & 0.60 \\
TOTAL & $\mathbf{4 . 5}$ & $\mathbf{0 . 1 5}$ & & $\mathbf{2 . 7 2}$ \\
\hline
\end{tabular}

Estos 4.5 minutos se tienen que asociar a todas las piezas de bambú de un proyecto, independientemente de su tamaño. Este resultado supera de 90 segundos las conclusiones de otro estudio (Chinchayán Plasencia, 2016), seguramente por el proceso de selección que se contempló aquí. 


\section{TIEMPOS Y COSTOS DE LAS UNIONES REALIZADAS EN EL PISO}

En función a los costos unitarios y los tiempos registrados, se elaboró una ficha técnica que detalla los procesos de fabricación/instalación de cada unión y su costo bruto correspondiente. La síntesis se presenta en la siguiente tabla.

Tabla 8

Costos y tiempos de armado (en el piso) de las uniones estudiadas

\section{$\stackrel{ }{\circ}$ Ilustración \\ Costo/unidad Tiempo armado. \\ (Sin proceso de habilitación)}

01 - Unión con pico de flauta

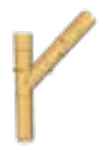

$\mathrm{S} / .12 .64$

$26 \mathrm{~min}$

02 - Unión con boca de pescado

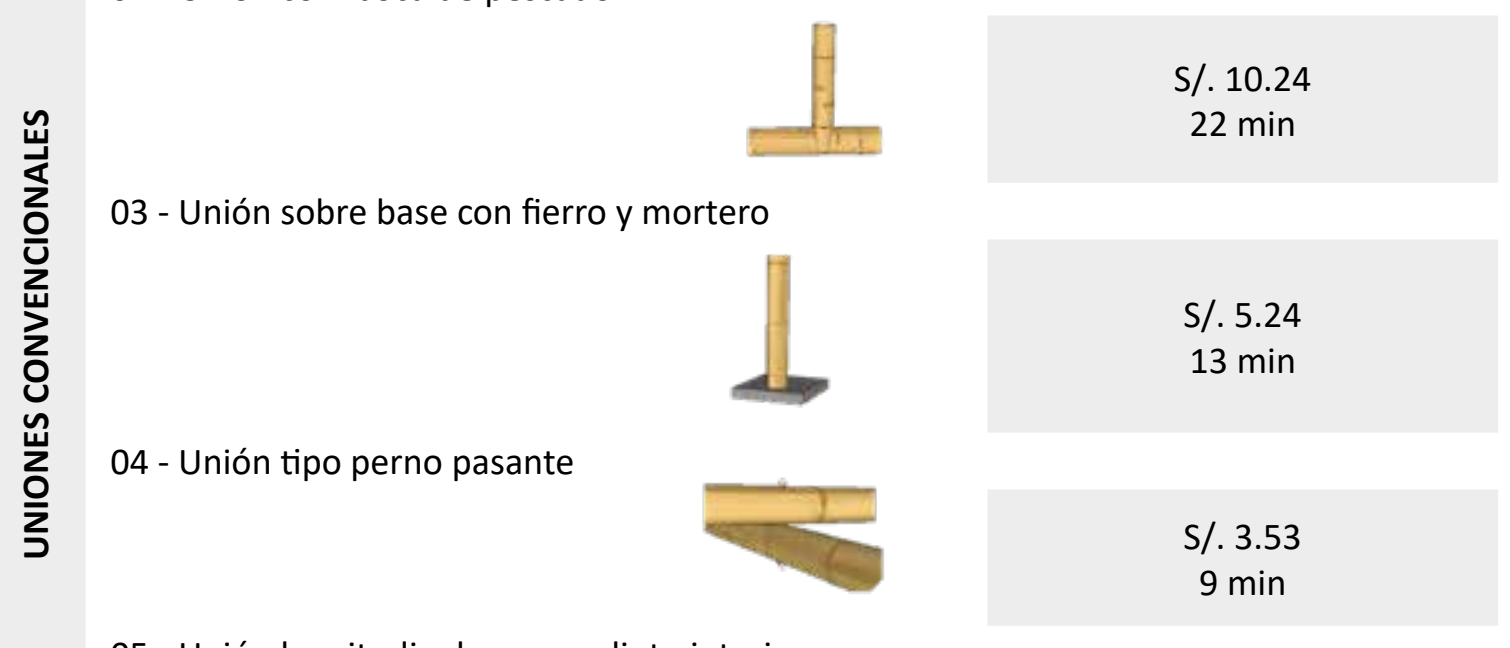

05 - Unión longitudinal con eucalipto interior

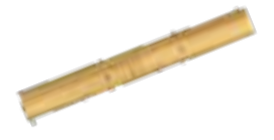

$\mathrm{S} / .11 .86$

$14 \mathrm{~min}$

06 - Unión perpendicular con tapa de madera

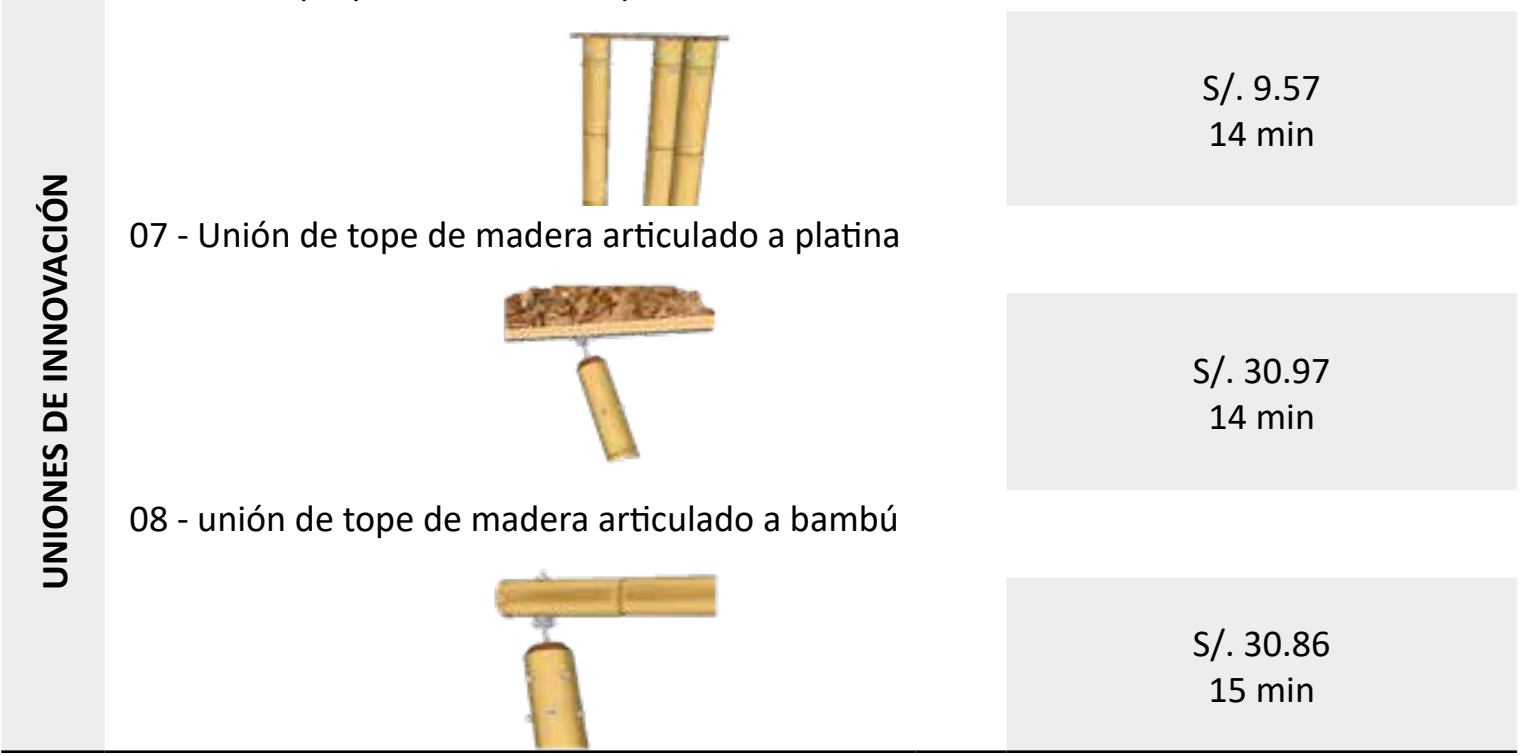




\section{Uniones en altura}

Como la mayoría de los trabajos en una obra, existe una gran diferencia de tiempos entre una actividad realizada en el piso y una actividad realizada en altura sobre un andamio, de una forma más o menos cómoda en función al tipo de configuración. Por esas variables, resultó complejo definir de forma exacta tiempos específicos. Sin embargo, la larga experiencia de maestros especializados en construcción con bambú permite establecer rangos. En este estudio, se entrevistó a tres de ellos y se promedió sus respuestas en la siguiente tabla.

Tabla 9

Estimación de tiempos para realizar actividades especificas por un experto con herramientas eléctricas.

\begin{tabular}{lcc}
\hline Actividad & $\begin{array}{c}\text { Piso } \\
\text { 1 experto } \\
\text { (minutos) }\end{array}$ & $\begin{array}{c}\text { Andamio } \\
1 \text { experto } \\
\text { +asistente } \\
\text { (minutos) }\end{array}$ \\
\hline $\begin{array}{l}\text { Corte y fijación } \\
\text { Boca de pescado }\end{array}$ & 10 & 20 \\
$\begin{array}{l}\text { Corte y fijación } \\
\text { Pico de flauta }\end{array}$ & 25 & 45 \\
$\begin{array}{l}\text { Perno pasante } \\
\text { Colocar una } \\
\text { pieza con doble } \\
\text { boca de pescado }\end{array}$ & $45^{*}$ & 6.5 \\
$\begin{array}{l}\text { Colocar una } \\
\text { pieza con doble } \\
\text { Pico de Flauta } \\
\text { Relleno de un } \\
\text { canuto con } \\
\text { mortero }\end{array}$ & 60 & 90 \\
\hline
\end{tabular}

*47 min de promedio en estudio Chinchayán, 2016 (para una pieza a un metro de altura próximamente)

Según los resultados, se constata que las actividades complejas toman entre $50 \%$ y $100 \%$ más tiempo que la misma actividad realizada en el piso, además de requerir un asistente.

\section{Comparación de caso}

Para evaluar la eficiencia de los conectores de innovación empleados en el prototipo de vivienda del IVUC, se comparó el costo de colocación de un pie amigo con dichas uniones versus la misma pieza colocada con uniones convencionales con corte en pico de flauta.

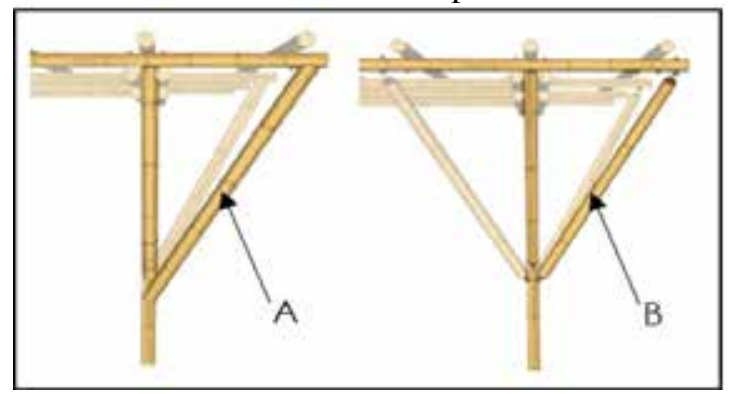

Figura 11. Pie amigo A) con doble pico de Flauta; B) con conectores de innovación

Tabla 10

Comparativo para el caso del pie amigo

\begin{tabular}{lcc}
\hline Ítems & $\begin{array}{c}\text { A- con } \\
\text { doble } \\
\text { pico de } \\
\text { flauta }\end{array}$ & $\begin{array}{c}\text { B- con doble } \\
\text { conector de } \\
\text { innovación }\end{array}$ \\
\hline $\begin{array}{l}\text { Tiempo bruto } \\
\text { prefabricación }\end{array}$ & 4 & 26 \\
$\begin{array}{l}\text { Tiempo de } \\
\text { armado }\end{array}$ & 90 & 9 \\
$\begin{array}{l}\text { Costo de } \\
\text { Mano de obra }\end{array}$ & 58.35 & 11 \\
$\begin{array}{l}\text { Costo } \\
\text { materiales }\end{array}$ & 2.90 & 55 \\
Costo Total & 61.25 & 66.0 \\
\hline
\end{tabular}

Los resultados muestran un costo directo similar entre las dos soluciones, con una diferencia de $7.7 \%$ en favor de la técnica tradicional, pero el tiempo de ejecución de la solución con conectores es inferior a la mitad, lo que permite reducir de forma significativa tiempos de obra, así como disminuye de forma significativa riesgos de accidentes ya que no se realizan ningún corte en altura. Cabe señalar que la solución convencional demanda una mano de obra muy experimentada y que cualquier error cometido en los cortes especiales significa volver a empezar desde cero, mientras los conectores permiten regular la dimensión de la pieza y evitar cualquier tipo de inconveniente. 


\section{FICHAS TÉCNICAS DE LAS UNIONES ESTUDIADAS}
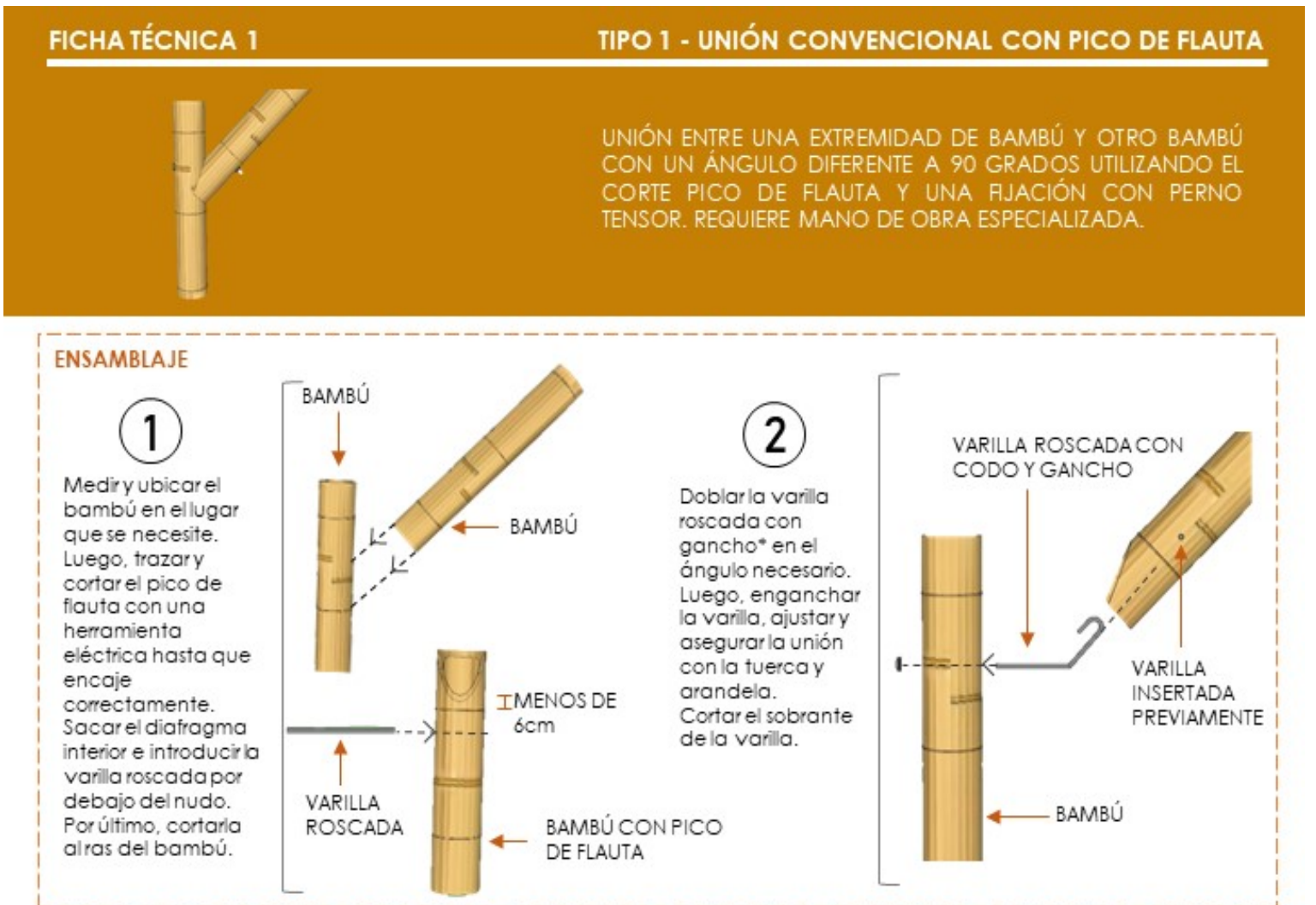

COSTOS

\begin{tabular}{|l|c|c|c|r|}
\hline Material & Unidad & Cant. & P.U & Parcial \\
\hline Varilla roscada $3 / 8^{\prime \prime}$ & $\mathrm{m}$ & 0.6 & 2.25 & 1.35 \\
\hline Tuerca & Unidad & 1 & 0.075 & 0.075 \\
\hline Arandela & Unidad & 1 & 0.05 & 0.05 \\
\hline \multicolumn{2}{|l}{} & & Subtotal & 1.48 \\
\cline { 3 - 5 }
\end{tabular}

\begin{tabular}{|c|c|c|c|c|}
\hline \multirow{2}{*}{ Pasos } & \multicolumn{2}{|c|}{ Tiempo } & \multirow{2}{*}{ P.U Mano de Obra } & \multirow{2}{*}{ Parcial } \\
\cline { 2 - 3 } & Min & HH & & \\
\hline 1 & 12 & 0.20 & 24.00 & 4.80 \\
\hline 2 & 8 & 0.133333 & 24.00 & 3.20 \\
\hline $2^{*}$ & 2 & 0.03 & 18.14 & 0.60 \\
\hline Subtotal & 22 & 0.366667 & - & 8.60 \\
\hline
\end{tabular}

Precio total sin IGV : 10.08

\section{DATOS EXTRA}

El corte para el pico de flauta se puede hacer con formón y martillo; en ese caso, el tiempo cambia a:

- Paso 1: $\quad 17$ min - Paso 2: $\quad 8 \mathrm{~min}$ -Total: $\quad 25 \mathrm{~min}$

*El gancho se forma calentando la varilla para facilitar el proceso. Se contabilizó dos (2) minutos por gancho.

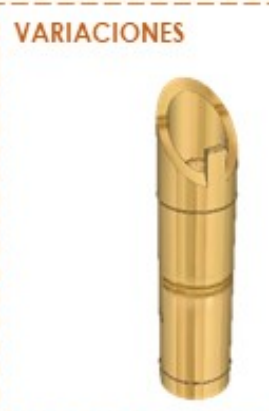

También se puede conservar una "oreja" ubicada en la parte más baja de la caña. Así se podrá insertar en la perforación ejecutada, previamente, en la otra caña.

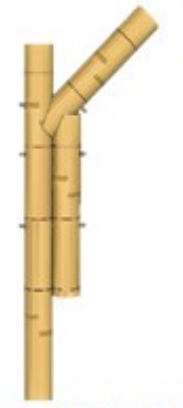

Unión de pico de flauta con bambú de refuerzo. El bambú de refuerzo se acopla con pico de flauta a la pieza armada y a su vez se emperna con la pieza vertical. 


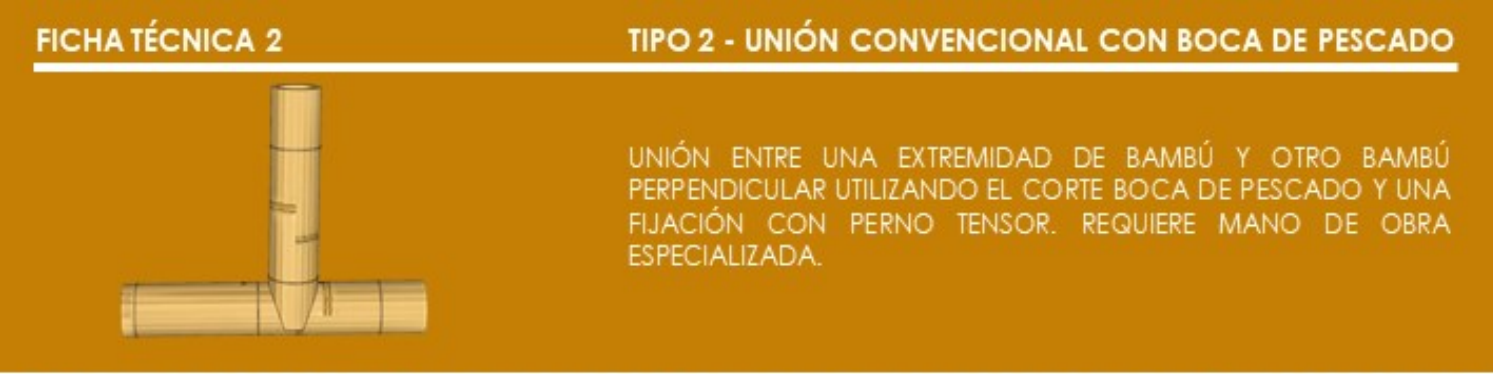

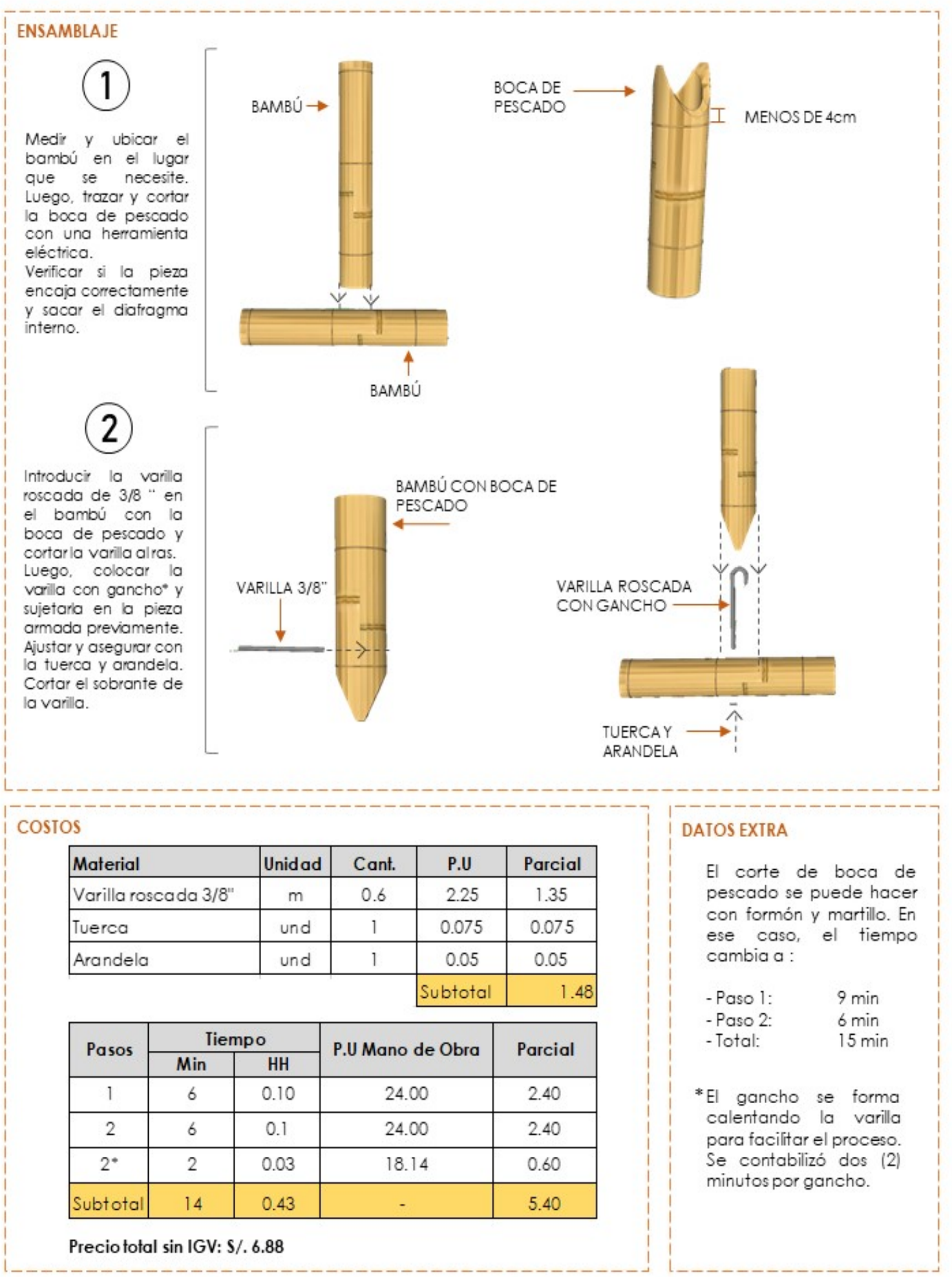


DESCRIPCIÓN Y ANÁLISIS DE COSTOS DE UNIONES CONVENCIONALES Y DE INNOVACIÓN EN LA CONSTRUCCIÓN CON BAMBÚ ROLLIZO

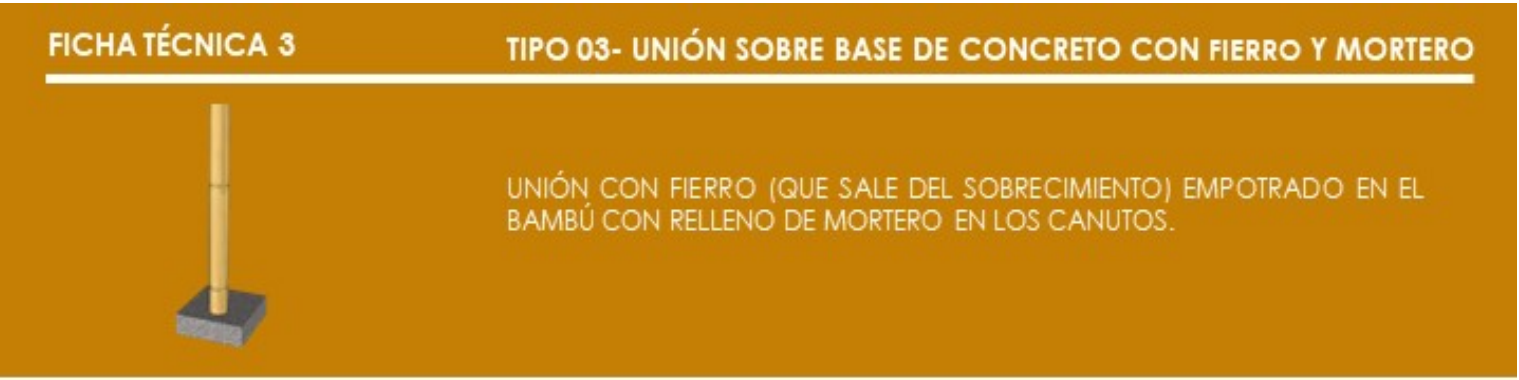

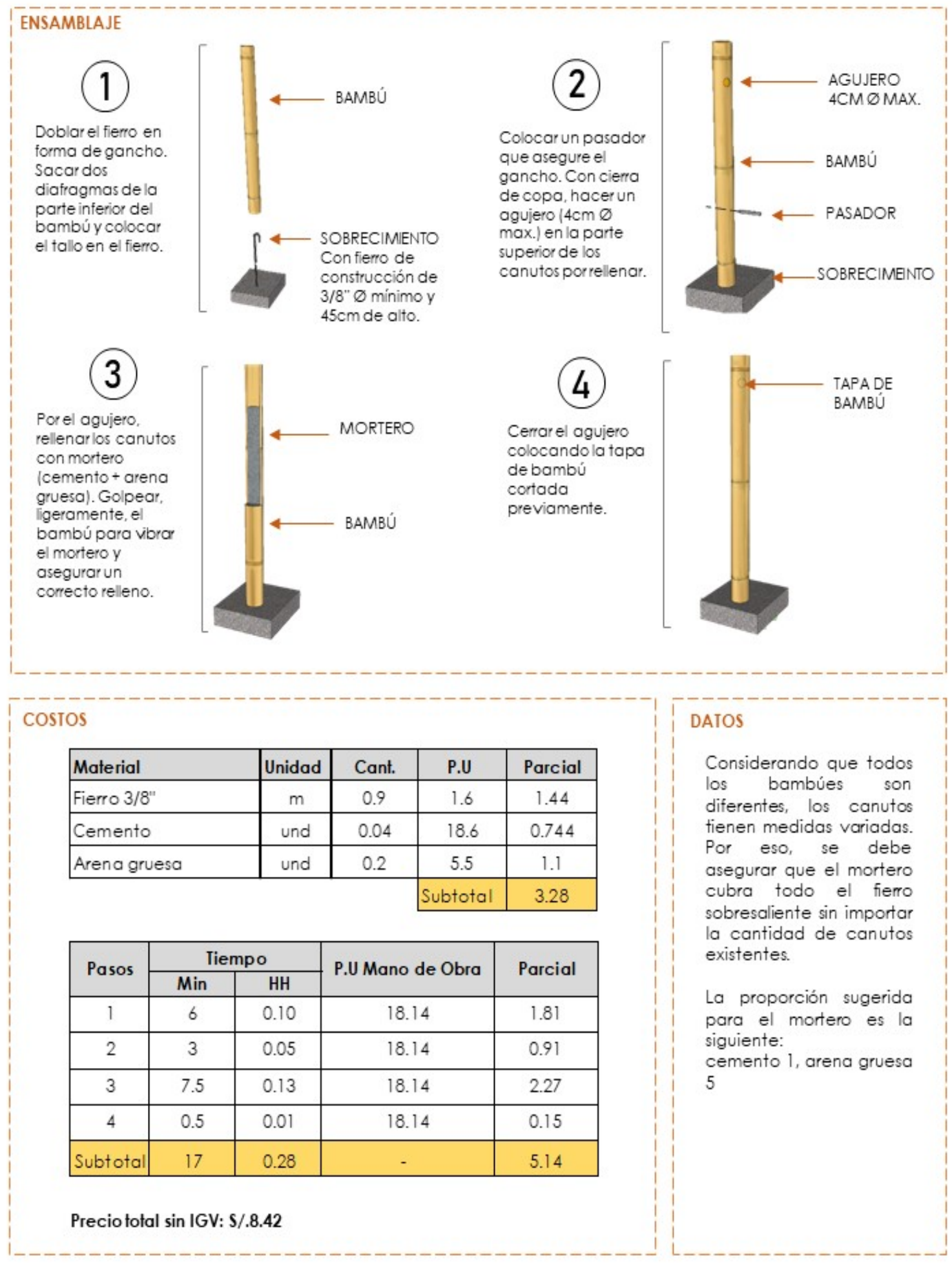


UNIÓN DE BAMBÚES YUXTAPUESTOS CON PERNO PASANTE. SE PUEDE REALIZAR PARA BAMBÚES ALINEADOS O CON CUALQUIER TIPO DE ÁNGULO. SE PUEDE TAMBIÉN EMPLEAR ESTA UNIÓN PARA CONECTAR MÁS DE DOS BAMBÚES A LA VEZ.

ENSAMBLAJE

(1)

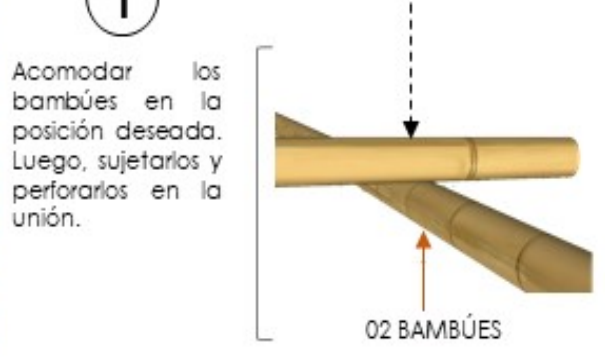

(2) En la perforación, insertar la varilla roscada /de $3 / 8$ " 0 $1 / 2^{\prime \prime}$ según se requiera) y asegurar por ambos lados con tuerca y arandela sin aplastar los bambúes. Cortar al ras e excedente de la varilla*.

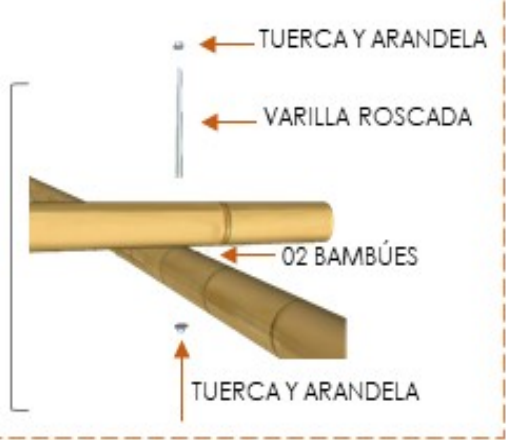

\section{COSTOS}

\begin{tabular}{|l|c|c|c|c|}
\hline Material & Unidad & Cant. & P.U & Parcial \\
\hline Varilla roscada $3 / 8^{\prime \prime}$ & $\mathrm{m}$ & 0.3 & 2.25 & 0.675 \\
\hline Tuerca $3 / 8^{\prime \prime}$ & und & 2 & 0.075 & 0.15 \\
\hline Arandela $3 / 8^{\prime \prime}$ & und & 2 & 0.05 & 0.1 \\
\hline
\end{tabular}

\begin{tabular}{|c|c|c|c|c|}
\hline \multirow{2}{*}{ Pasos } & \multicolumn{2}{|c|}{ Tiempo } & \multirow{2}{*}{ P.U Mano de Obra } & \multirow{2}{*}{ Parcial } \\
\cline { 2 - 3 } & Min & HH & & \\
\hline 1 & 1 & 0.02 & 18.14 & 0.30 \\
\hline 2 & 3.5 & 0.06 & 18.14 & 1.06 \\
\hline Subtotal & 4.5 & 0.08 & - & 1.36 \\
\hline
\end{tabular}

\section{Precio total sin IGV: S/.2.29}

\section{VARIACIONES}
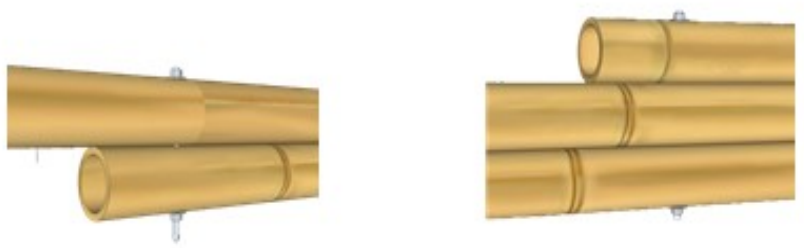

Para calcular el costo total de la unión, añadir $10 \mathrm{~cm}$ de varilla roscada por bambúes adicionales. 
DESCRIPCIÓN Y ANÁLISIS DE COSTOS DE UNIONES CONVENCIONALES Y DE INNOVACIÓN EN LA CONSTRUCCIÓN CON BAMBÚ ROLLIZO

\section{FICHA TÉCNICA 5}

TIPO 05- UNIÓN LONGITUDINAL CON MADERA INTERIOR

UNIÓN PARA CONECTAR LAS EXTREMIDADES DE DOS BAMBÚES

ALINEADOS EMPLEANDO UN TROZO DE EUCALIPTO

INCRUSTADO AL INTERIOR DE LOS TALLOS Y ASEGURADO CON

PERNOS DE $3 / 8$.

\section{ENSAMBLAJE}

(1) eucalpto y refirar los diafragmas interiores de la extremidad de los bambúes. Comprobar que la madera encaja bien (no debe quedar muy suelta).

\section{(2)}

Introducir el eucalipto en los dos bambúes y asegurarlo con dos varilas roscada de $3 / 8$ " colocadas de forma perpendicular en cado bambú. Cortar al ras los excedentes.

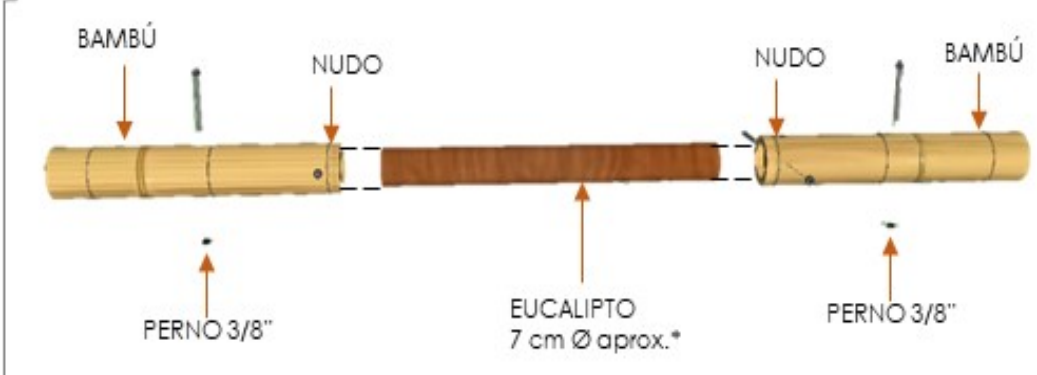

\section{cosios}

\begin{tabular}{|c|c|c|c|c|}
\hline Material & Unidad & Cant. & P.U & Parcial \\
\hline Varilla roscada $3 / 8^{\prime \prime}$ & $\mathrm{m}$ & 0.6 & 2.25 & 1.35 \\
\hline Eucalipto & $\mathrm{m}$ & 0.8 & 4.5 & 3.6 \\
\hline Arandelas & und & 8 & 0.05 & 0.4 \\
\hline Tuercas & und & 8 & 0.075 & 0.6 \\
\hline & & & Subtotal & 5.95 \\
\hline
\end{tabular}

\begin{tabular}{|c|c|c|c|c|}
\hline \multirow{2}{*}{ Pasos } & \multicolumn{2}{|c|}{ Tiempo } & \multirow{2}{*}{ P.U Mano de Obra } & \multirow{2}{*}{ Parcial } \\
\cline { 2 - 3 } & Min & HH & & 2.42 \\
\hline 1 & 8 & 0.13 & 18.14 & 4.00 \\
\hline 2 & 10 & 0.17 & 24.00 & 6.42 \\
\hline Subtotal & 18 & 0.30 & - & \multicolumn{2}{|c|}{} \\
\hline
\end{tabular}

Precio total sin IGV: S/.12.37

\section{DATOS EXIRA}

* El diámetro del eucalipto puede variar según el diámetro interior del bambú. Algunas veces es necesario entallar la madera para que encaje. 


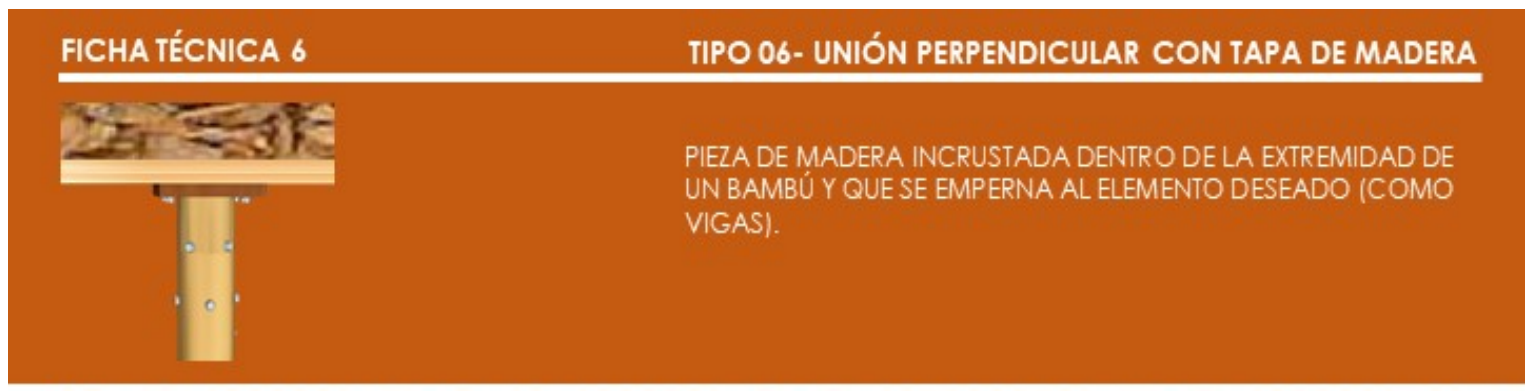

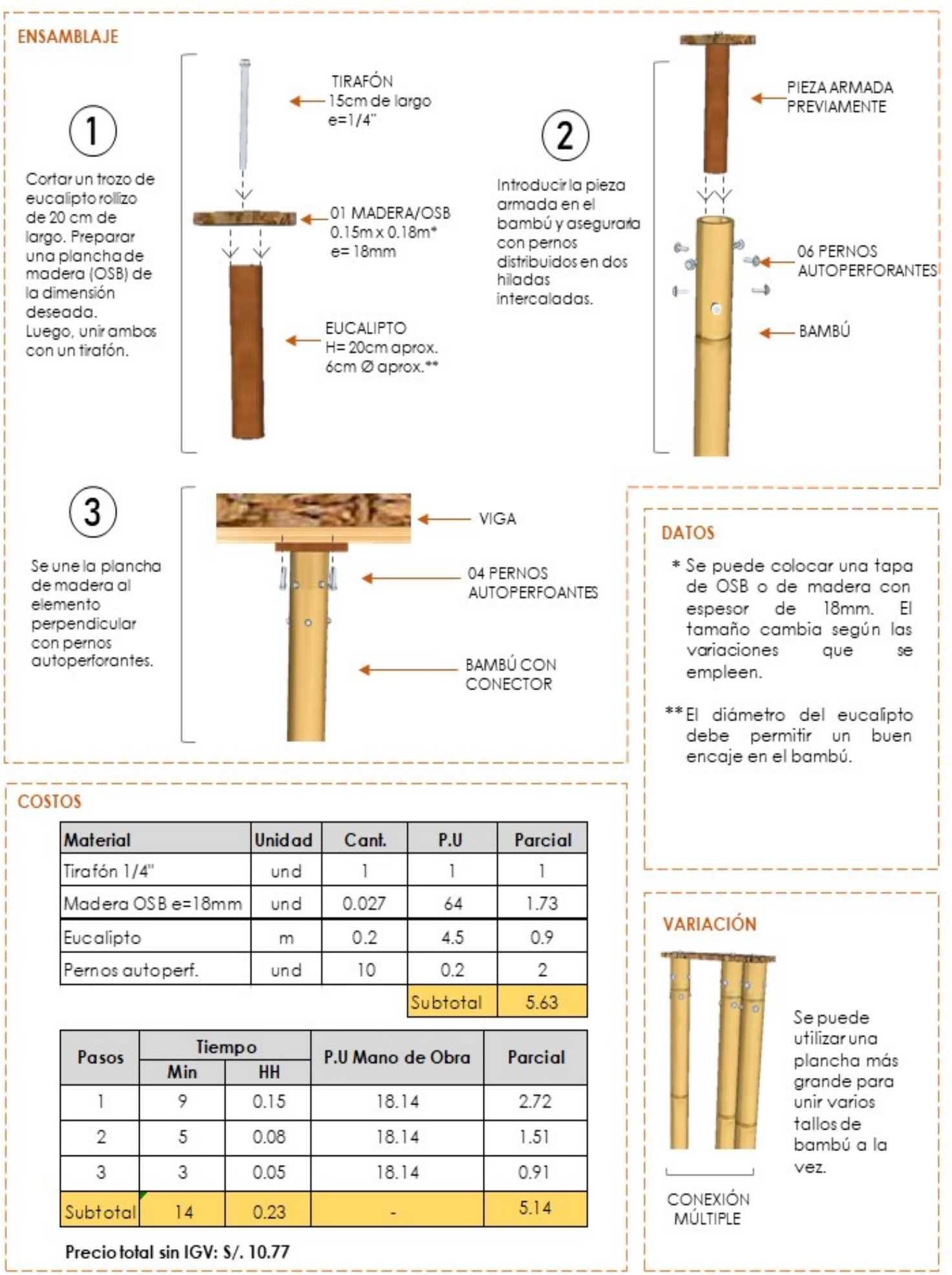


DESCRIPCIÓN Y ANÁLISIS DE COSTOS DE UNIONES CONVENCIONALES Y DE INNOVACIÓN EN LA CONSTRUCCIÓN CON BAMBÚ ROLLIZO
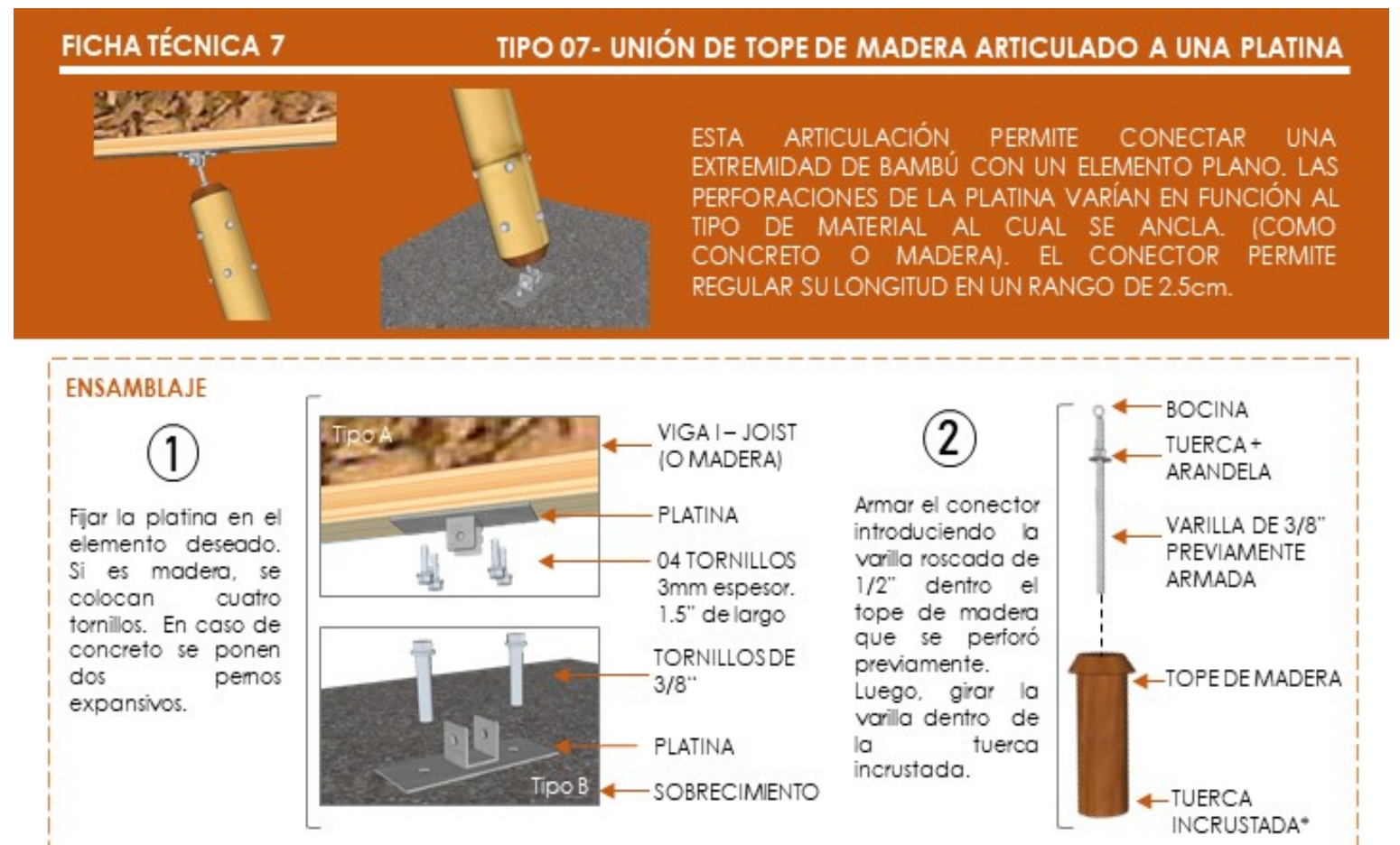

\section{(3)}

Insertar el tope de madera en el bambú. Asegurario con dos hileras intercalodas de tornillos que deben estar separadas $(6 \mathrm{~cm}$ aprox). Al terminar el proceso. debe verificarse que la varilla siga girando.

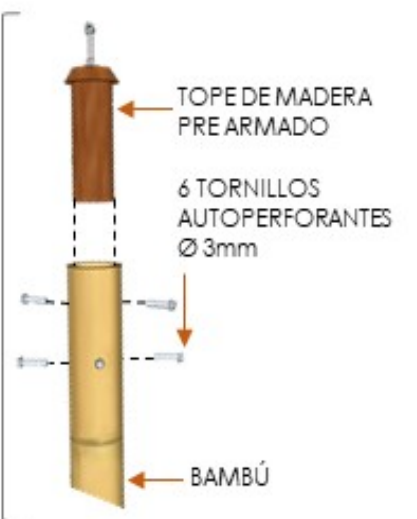

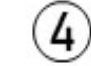

Conectar la bocina a la platina mediante un perno de $\varnothing$ $3 / 8$ ".

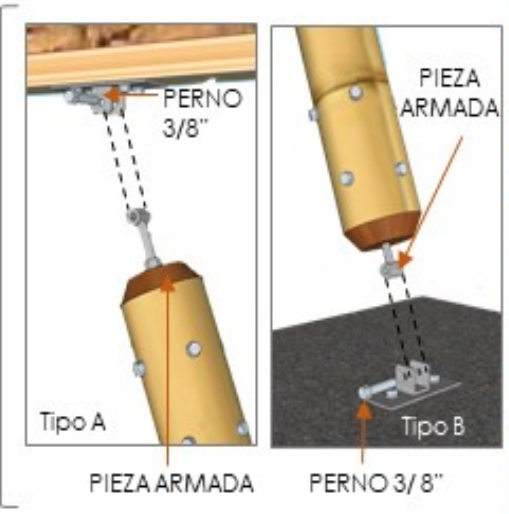

\begin{tabular}{|l|c|c|c|c|}
\hline Material Tipo 03-A & Unidad & Cant. & P.U & Parcial \\
\hline Tope de madera & pza & 1 & 7 & 7 \\
\hline Varilla con bocina & pza & 1 & 4.4 & 4.4 \\
\hline Tornillos autoperf. & und & 10 & 0.2 & 2 \\
\hline Arandelas $1 / 2^{\prime \prime}$ & und & 2 & 0.1 & 0.2 \\
\hline Tuerca $1 / 22^{\prime}$ & und & 3 & 0.135 & 0.405 \\
\hline Platina metálica & pza & 1 & 8 & 8 \\
\hline Perno 3/8" & und & 1 & 0.5 & 0.5 \\
\hline
\end{tabular}

\begin{tabular}{|c|c|c|c|c|}
\hline \multirow{2}{*}{ Pasos } & \multicolumn{2}{|c|}{ Tiempo } & \multirow{2}{*}{ P.U Mano de Obra } & \multirow{2}{*}{ Parcial } \\
\cline { 2 - 3 } & Min & HH & \\
\hline 1 (tipo A) & 3 & 0.05 & 18.14 & 0.91 \\
\hline 2 & 4 & 0.07 & 18.14 & 1.21 \\
\hline 3 & 5 & 0.08 & 18.14 & 1.51 \\
\hline 4 & 2 & 0.03 & 22.94 & 0.76 \\
\hline Subtotal & 14 & 0.23 & - & 4.39 \\
\hline
\end{tabular}

\section{DATOS EXTRA}

* Después del ensamblaje de uniones en ambos extremos del bambú se procede a colocarlo en la estructura general. Si se necesitara regular el tamaño del bambú, el tiempo a considerar es de cinco minutos.

** Para el Tipo B (en concreto), se utiliza otro tipo de fiación; por ende, el costo del material varía:

\begin{tabular}{|c|c|c|c|}
\hline Materid & Cant. & P.U & Pacid \\
\hline $\begin{array}{c}\text { Perno de } \\
\text { expan. }\end{array}$ & 2 & 1.50 & 3.00 \\
\hline
\end{tabular}

Este caso:

Precio de material : $\$ / .24 .70$ 

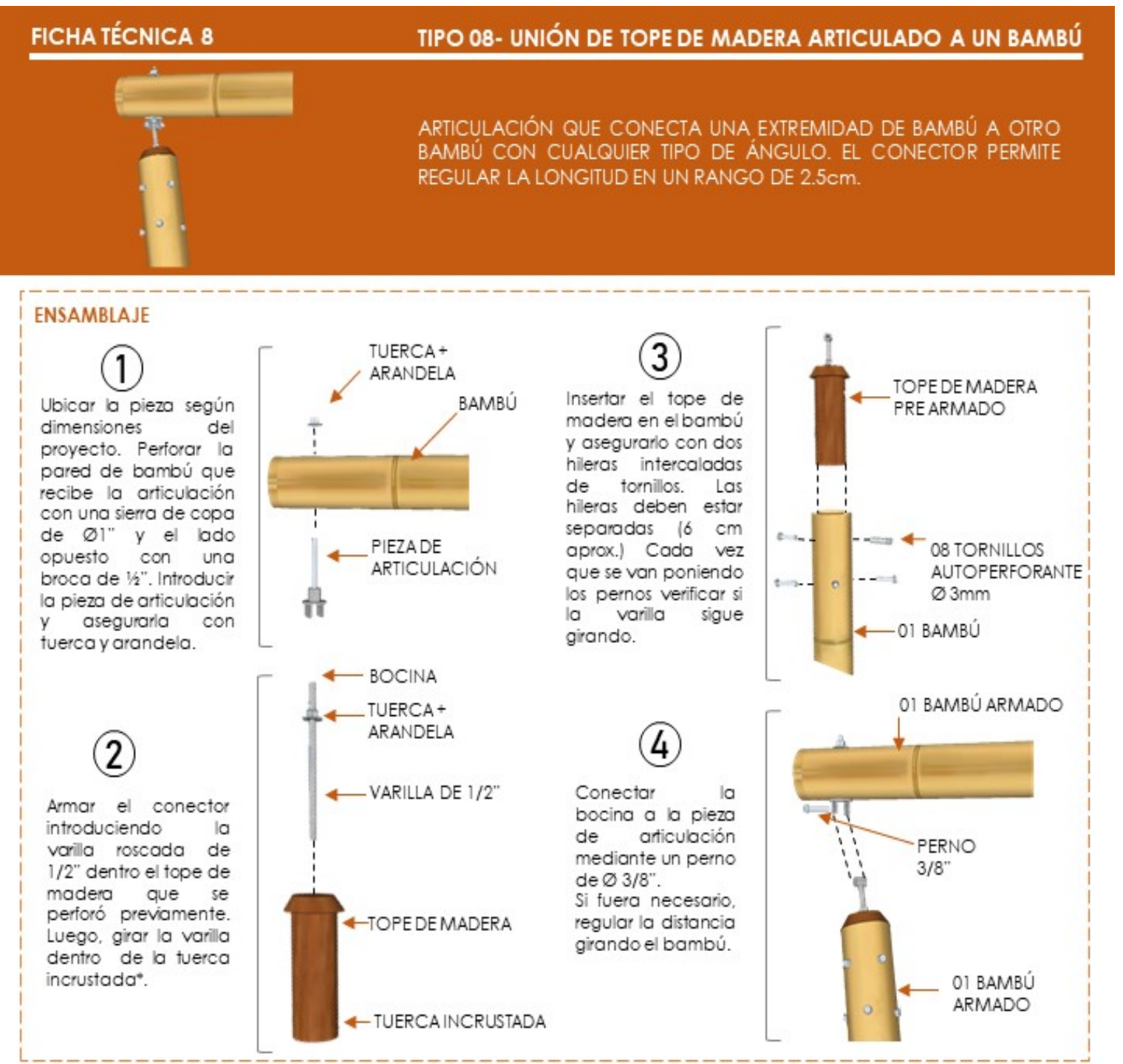

METRADO
\begin{tabular}{|l|c|c|c|c|}
\hline Material & Unidad & Cant. & P.U & Parcial \\
\hline Tope de madera & pza & 1 & 7 & 7 \\
\hline Pieza de articulación & pza & 1 & 10.3 & 10.3 \\
\hline Varilla con bocina & pza & 1 & 4.4 & 4.4 \\
\hline Tornillos autoperf. & und & 6 & 0.2 & 1.2 \\
\hline Perno $3 / 8^{\prime \prime}$ & und & 1 & 0.5 & 0.5 \\
\hline Arandelas $1 / 2^{\prime \prime}$ & und & 2 & 0.1 & 0.2 \\
\hline Tuercas $1 / 2^{\prime \prime}$ & und & 3 & 0.135 & 0.405 \\
\hline
\end{tabular}

\begin{tabular}{|c|c|c|c|c|}
\hline \multirow{2}{*}{ Pasos } & \multicolumn{2}{|c|}{ Tiempo } & \multirow{2}{*}{ P.U Mano de Obra } & \multirow{2}{*}{ Parcial } \\
\cline { 2 - 5 } & Min & HH & & 1.21 \\
\hline 1 & 4 & 0.07 & 18.14 & 1.21 \\
\hline 2 & 4 & 0.07 & 18.14 & 1.51 \\
\hline 3 & 5 & 0.08 & 18.14 & 0.76 \\
\hline 4 & 2 & 0.03 & 22.94 & 4.70 \\
\hline Subtotal & 15 & 0.25 & - & \multicolumn{1}{c}{} \\
\hline
\end{tabular}

Precio total sin IGV: S/.28.7I

\section{DATOS EXTRA}

* En la parte inferior del tope de madera se encuentra una tuerca encastrada en la madera que permite regular la posición de la varila con bocina
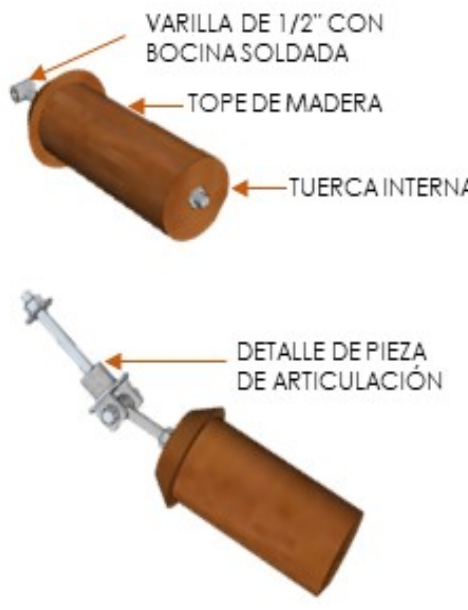


\section{Conclusiones}

Los resultados muestran que existe una notable diferencia del tiempo de ejecución entre una unión efectuada en el piso y una realizada en altura, sobre todo para uniones que demandan cortes especiales. Por lo tanto, es recomendable favorecer diseños que permitan ejecutar la mayor parte del trabajo en el piso, y en particular las uniones más complejas. Se confirma así observaciones sobre los beneficios de la prefabricación para optimizar los procesos en la construcción con bambú (Barnet \& Jabrane, 2017), en los cuales se saca provecho del muy bajo peso de ese material para pre-armar grandes componentes estructurales.

En procesos de prefabricación, las uniones convencionales, y en particular la del perno pasante, son las menos costosas y por lo tanto siguen vigente si se cuenta con mano de obra calificada. Sin embargo, para conexiones en altura, las uniones con conectores preinstalados, que demandan únicamente colocar un perno in situ, resultan ser económicamente competitivas. Como ventaja, hacen ganar tiempo en la obra, reducen significativamente el trabajo riesgoso en altura y aseguran la calidad de la conexión sin requerir una mano de obra especializada. Además, son regulables y fácil de desmontar, características que no ofrecen las uniones convencionales. Por lo tanto, representan una alternativa efectiva para sustituir las uniones complejas en una obra y cualquier tipo de construcción que tiene vocación a ser montada muy rápidamente y/o desmontada.

Paraampliarel rangode uso deesas uniones, se tendría que disminuir significativamente los costos de los conectores; de esa manera se volverían atractivas hasta en los procesos de prefabricación.

Si bien las uniones de innovación no han presentado fallas en los prototipos construidos y han demostrado una buena ductilidad en ensayos exploratorios (solo para esfuerzos paralelos al tallo de bambú), resultaría importante realizar estudios detallados de su comportamiento estructural.

\section{Reconocimientos}

Por su participación en los procesos de desarrollo y fabricación de prototipos, se agradece a las siguientes personas: Hector Llaven, Manuel Pińa, Victor Barraza, Remi Albert, Eduardo Perilla y el equipo del IVUC en general. También se reconoce los aportes de los expertos en construcción con bambú que fueron consultados en este estudio: Maximiliano Galarza, Jairo Llamo y Carlos Huayta. 


\section{Referencias}

Barnet, Y., \& Jabrane, F. (2017). Diseño de proyectos con bambú en Lima como estrategia de difusión de un método constructivo alternativo y sostenible. Campus, 22(23).

Barnet, Y., \& Jabrane, F. (2019). Conectores de extremidades de bambú para estructuras exploración de un sistema de incrustación en la pared interna del tallo. Campus, 24(27).

Barnet, Y., \& Jabrane, F. (2019). Diseñar y Construir en bambú en el Perú. Lima: Fondo editorial USMP.
Chinchayán, L. (2016). Aportes de mano de obra y materiales, para la creación de partidas en la construcción con bambú. Lima.

Ministerio de Vivienda, Construcción y Saneamiento. (2012). Reglamento Nacional de Edificación. E100 Bambú.

Revista Costos. (2020). Suplemento técnico. Costos(304). 